\title{
Biodegradation of Polymethylmethacrylate Bone Cement May Not Be a Serious Issue in Total Hip Arthroplasty- Retrieval Study for Knoop Hardness and Young's Modulus*
}

\author{
Masaaki Maruyama ${ }^{1,2 \#}$, William N. Capello ${ }^{2}$ \\ ${ }^{1}$ Department of Orthopaedic Surgery, Indiana University Medical Center, Clinical Building Suite, Indianapolis, USA; ${ }^{2}$ Department of \\ Orthopaedic Surgery, Shinonoi General Hospital, Nagano, Japan. \\ Email: "
}

Received August $6^{\text {th }}, 2013$; revised September $7^{\text {th }}, 2013$; accepted September $22^{\text {nd }}, 2013$

Copyright (C) 2013 Masaaki Maruyama, William N. Capello. This is an open access article distributed under the Creative Commons Attribution License, which permits unrestricted use, distribution, and reproduction in any medium, provided the original work is properly cited.

\begin{abstract}
Introduction: To investigate a long-term in vivo deterioration of polymethylmethacrylate (PMMA) bone cement over time, we evaluated retrieved PMMA cement in terms of chemical elements presenting in the cement using energy dispersive analysis of X-rays; Knoop hardness; and the Young's modulus using scanning acoustic microscopy. Materials and Methods: For mechanical evaluation, we could neglect the influences of entrapped air bubbles or blood by the use of small specimens. The study was based on thirteen cement samples (six used in the acetabulum and seven in the femur) derived from eight patients (age at revision surgery: mean 72.5, range 68 to 79). All of these samples were Simplex-P ${ }^{\circledR}$ cement. They were functioning well at least ten years after the previous surgery. Duration until revision surgery was ranged 12 to 25 years (average, 17.4 years). The reason for revision was aseptic mechanical loosening. Twenty samples of Simplex- $\mathrm{P}^{\circledR}$ cement were served by manually mixing as a control. Results: The average of the hardness of the cement was $17.0 \pm 1.2$ (range, 13.4 - 20.6). In the control, the hardness was $17.8 \pm 1.5$ (range, 14.0 - 24.6). There was no significant difference between these values. The mean of Young's modulus of the cement was $5.61 \pm 0.19 \mathrm{GPa}$ (range, 5.09 - 6.10). In the control, the modulus was $6.04 \pm 0.13 \mathrm{GPa}$ (range, 5.68 - 6.45). Although the modulus was significantly less than that of the control, there was only $7 \%$ decrease in average between twelve and twenty-five years in vivo. Conclusions: Our results suggest that long-term implantation and functional loading in vivo may not be the limiting factor in the mechanical integrity of the bone cement.
\end{abstract}

Keywords: Polymethylmethacrylate Bone Cement; Biodegradation; Total Hip Arthroplasty; Retrieval Study; Knoop Hardness; Young's Modulus

\section{Introduction}

Since Charnley [1] introduced polymethylmethacrylate (PMMA) bone cement used as a grout to provide mechanical fixation of the hip prostheses to bone, and the cement has been widely used in total hip arthroplasty or hemi-arthroplasty. The cement must endure considerable

\footnotetext{
*Comments: Recently, good longevity of cemented total hip arthroplasty was documented in many articles. One of the factor contributed to the good results was mechanical properties of the polymethylmethacrylate bone cement with little biodegradation. Although there are some limitations for the retrieval study, we would like to prove biodegradation of the cement.

${ }^{\#}$ Corresponding author.
}

stresses in vivo applications, because its main function is transference of load from the prosthesis to the bone. In addition, the cement has the Young's modulus which was ranked between that of the cancellous bone and the cortical bone. As the mechanical properties of polymeric materials are, in general, time-dependent [2], degradation or deterioration of the cement may influence on the long term results of total joint replacement surgery. Although recent reports have confirmed relatively good long-term results of the cemented hip arthroplasty, the rates of loosening in the reports gradually increase over time [3-5]. Our hypothesis is that biodegradation of PMMA cement 
may not contribute to mechanical loosening of the hip prostheses in long time survival.

Concerning the effect of time on mechanical properties of the PMMA cement, there were several reports dealing with a possible deterioration of the cement. Jaffe et al. [6] stored the cement specimens in bovine serum at $37^{\circ} \mathrm{C}$ up to two years and found no deterioration both in static properties and in compression-fatigue behavior. During a study of the causes of failed Judet prosthesis, Scales and Zarek [7] found some evidence of alteration in the mechanical properties of acrylic resin in the course of time. Lee et al. [8] stored bone cement specimens in isotonic saline solution at $37^{\circ} \mathrm{C}$ and found an increase in compressive strength after seven days. However, they mentioned that the strength decreased by $7 \%$ and $8.5 \%$ after 6 and 12 months, respectively. Rostoker et al. [9] reported that the PMMA cement removed from rabbits showed a significant drop in fracture stress, which was determined by a three-point bending test, during the period between 12 and 26 months after implantation. With regard to acrylic cement retrieved from patients, Holz et al. [10] reported that compressive strength was markedly decreased between one and two years after implantation. But they concluded that it was not the aging of the cement. The follow-up period of these reports was 26 months or less, which was too short to evaluate the long term effects of implantation of PMMA. In the literature, little has been written about the mechanical properties of the cement which functioned over ten years in an in vivo environment.

The purpose of our study was to investigate both Knoop hardness and Young's modulus of the retrieved PMMA cement which normally functioned at least ten years after cemented hemi- or total hip arthroplasty. In addition, we also aimed to detect chemical elements presenting in the cement and to know some effects of in vivo environment.

\section{Materials and Methods}

Between August and December, 1995, forty seven patients underwent revision total hip arthroplasty in Indiana University Medical Center and the satellite hospitals. The main cause for the revision was aseptic mechanical loosening. Loosening due to infection was excluded from the study, since it seemed to be changed normal physiological condition around the cement. The samples retrieved by the ultrasonic tool, such as ULTRADRIVE ${ }^{\circledR}$ (Biomet Inc., Warsaw, Indiana, USA), also were excluded from the study, because the chemical fabrication of the cement might be greatly altered due to extremely high temperature induced by the tool. Nine of the patients (fifteen cement samples: seven used in the acetabulum and eight in the femur) had functioned well as a part of artificial hip joint during at least ten years after the previous surgery. PMMA samples from these patients were cleared of bone and soft tissue, and washed out blood and debris. To avoid virus infection in processing them into test specimens and to prevent from contamination and breeding of microorganisms during storage at room temperature $\left(23^{\circ} \mathrm{C} \pm 1^{\circ} \mathrm{C}\right)$, they were immersed in $10 \%$ formalin for 72 hours. Subsequently, formalin was washed out by using distilled water and each sample was cut into two specimens. The first set of specimens was stored in air at the room temperature for an average of 15 weeks (range, 10 to 20 weeks). They were subjected to the elemental analysis. The second set of specimens was stored in physiological saline solution $(0.9 \%$ sodium chloride) at the room temperature for an average of 7 weeks (range, 2 to 12 weeks).

Although two of the retrieved cement samples were known as Simplex- $\mathrm{P}^{\circledR}$ (Howmedica, Rutherford, New Jersey, USA), the brands of the remaining thirteen samples were unknown. Simplex- $\mathrm{P}^{\circledR}$ cement consisted of the following components: a liquid containing methylmethacrylate monomer, N, N-dimethyl-p-toluidine for promoter of polymerization, and a small amount of hydroquinone for inhibitor; and a solid containing methyl methacrylate-styrene copolymer, benzoyl peroxide for initiator, and barium sulfate for radiopaque property. We used Fourier transform infrared (FT-IR, Nicolet 20SXB FT-IR Spectrophotometer, Nicolet, Fremont, California, USA) to identify styrene, which is specific for Simplex- $\mathrm{P}^{\circledR}$ cement. As a result, two (No. 5-a and 5-b) of the remaining thirteen samples did not include styrene element and eleven previously unknown samples were identified a Simplex- $\mathrm{P}^{\circledR}$ cement. After adding two previously known Simplex- $\mathrm{P}^{\circledR}$ samples, the subsequent studies were based on thirteen cement samples (six used in the acetabulum and seven in the femur) derived from eight patients (age at revision surgery: mean 72.5 , range 68 to 79 ) (Table 1). They were functioned well during ten years or more after the previous surgery. Duration until revision surgery was ranged 12 to 25 years (average, 17.4 years).

Each sample was sectioned radially (cement used in the acetabulum) or transversely (cement used in the femur) by using of thin sectioning machine (South Bay Technology Inc., California, USA) under water cooling. The thickness of the test specimens was set for $4 \mathrm{~mm}$ to measure Knoop hardness and $0.7 \mathrm{~mm}$ to assess Young's modulus. The sectioned surfaces were polished using polishing machines (LECO DS-20, VARI/POLTM, and VP150, LECO Corporation, Michigan, USA) with metallographic papers (grit \#240, 360, 400, and 600) under water to achieve the smooth surface. 
Arthroplasty-Retrieval Study for Knoop Hardness and Young's Modulus

Table 1. Retrieved polymethylmethacrylate bone cement samples.

\begin{tabular}{|c|c|c|c|c|c|c|c|}
\hline $\begin{array}{l}\text { Sample } \\
\text { No. }\end{array}$ & Diagnosis & Gender & $\begin{array}{c}\text { Age at } \\
\text { Revision }\end{array}$ & Used with: & $\begin{array}{c}\text { Duration until } \\
\text { Revision (years) }\end{array}$ & $\begin{array}{l}\text { Causes of } \\
\text { Revision }\end{array}$ & $\begin{array}{l}\text { Cement } \\
\text { fracture }\end{array}$ \\
\hline $1-\mathrm{a}$ & Osteoarthritis & Male & 74 & Acetabular Socket & 18 & Aseptic Loosening & - \\
\hline $1-b$ & Osteoarthritis & Male & 74 & Femoral Stem & 18 & Aseptic Loosening & + \\
\hline 2 & Osteoarthritis & Female & 70 & Femoral Stem & 15 & Aseptic Loosening & - \\
\hline $3-\mathrm{a}$ & Osteoarthritis & Female & 75 & Femoral Stem & 12 & Aseptic Loosening & + \\
\hline $3-b$ & Osteoarthritis & Female & 75 & Acetabular Socket & 12 & Aseptic Loosening & - \\
\hline 4 & Osteoarthritis & Female & 79 & Acetabular Socket & 14 & Aseptic Loosening & - \\
\hline $6-\mathrm{a}$ & Osteoarthritis & Female & 74 & Femoral Stem & 16 & Aseptic Loosening & - \\
\hline $6-b$ & Osteoarthritis & Female & 74 & Acetabular Socket & 16 & Aseptic Loosening & - \\
\hline $7-\mathrm{a}$ & Osteoarthritis & Male & 68 & Femoral Stem & 20 & Aseptic Loosening & + \\
\hline $7-b$ & Osteoarthritis & Male & 68 & Acetabular Socket & 20 & Aseptic Loosening & - \\
\hline $8-\mathrm{a}$ & Osteoarthritis & Female & 70 & Femoral Stem & 25 & Osteolysis & - \\
\hline $8-b$ & Osteoarthritis & Female & 70 & Acetabular Socket & 25 & Aseptic Loosening & + \\
\hline 9 & Rheumatoid Arthritis & Female & 72 & Femoral Stem & 15 & Osteolysis & - \\
\hline
\end{tabular}

Twenty samples of Simplex-P ${ }^{\circledR}$ cement $(5 \mathrm{~mm}$ width and $30 \mathrm{~mm}$ length) were served by manually mixing as a control, because most of the retrieved cement were made by manually mixing in air (no vacuum mixing) when the patients underwent total hip arthroplasty 12 to 25 years ago. They were stored in physiological saline solution for three weeks after mixing at the room temperature to eliminate any effect of after polymerization on the results. Then, all of the samples were also immersed in $10 \%$ formalin for 72 hours. Subsequently, formalin was washed out and the specimens were stored in physiological saline solution for additional three weeks. Test specimens were made by cutting and polishing as the same manner (the same sizes and thickness) as the above mentioned.

Porosity $\left(\mathrm{p}_{\mathrm{s}}\right)$ and density $(\rho)$ of the samples were calculated on the $0.7 \mathrm{~mm}$-thick specimens. Contact microradiography (CMR) was taken for each specimen. The number (n) and radius (r) of the entrapped air bubbles was counted by direct observation on the radiography using light microscopy. Five fields of view were randomly selected for each specimen. Porosity was estimated through the following formula [11]:

$\mathrm{p}_{\mathrm{s}}=\frac{[\text { Sum of volumes of pores in the field of view }(\mathrm{S})]}{[\text { Area of the field of view }] \times[\text { thickness of specimen }]}$

where, $S=4 \pi / 3 \cdot \sum_{i=1}^{n} \mathrm{r}_{i}^{3}$

$n$ : the number of the entrapped air bubbles, $r$ : radius of the entrapped air bubbles

The average value was regarded as the porosity of the specimen.

Density was calculated by the following formula:

$$
\rho_{a}=0.789 \cdot w /\left(w-w_{e}\right)
$$

where, $\rho_{a}$ : apparent density affected by the porosity of the specimen, $w$ : weight of the specimen, $w_{e}$ : weight of the specimen in $100 \%$ ethanol, density of $100 \%$ ethanol $=0.789$.

The apparent density was corrected by the porosity of the specimen. As a result, true density of the specimen $(\rho)$ was calculated as follows:

$$
\rho=\rho_{a} /\left(1-\mathrm{p}_{\mathrm{s}}\right)
$$

where, $p_{s}$ : porosity of the samples

\subsection{Detection of Chemical Elements Presenting in the Retrieved PMMA Cement}

All of the retrieved bone cement samples were examined using energy dispersive analysis of X-rays (EDAX) (9900-EDS X-ray Fluorescence, Philips Electronic Co., Mahwah, New Jersey, USA). All specimens were sterilized with a double dose of gas plasma. Thin films were pressed at $180^{\circ} \mathrm{C}$ from all of the samples and were investigated by the EDAX analyzer at $5.00 \mathrm{KEV}$. Chemical elements were identified from X-ray dispersive pattern. Simplex- $\mathrm{P}^{\circledR}$ cement was composed of carbon, hydrogen, oxygen, nitrogen, barium and sulfur. These elements were excluded from the detection because the EDAX was qualitative analysis.

\subsection{Knoop Hardness}

Knoop hardness measurements were obtained from the sectioned surface of each $4 \mathrm{~mm}$-thick specimen using Hardness Tester (LECO M-400, LECO Corporation, Mi- 
chigan, USA). The diamond indenter point was kept on the surface for 20 second with a $50 \mathrm{~g}$ load. The measurements were performed at the area less than $0.5 \mathrm{~mm}$ distant from the surface to the bone (A), the middle area of the specimen (B), and the area less than $0.5 \mathrm{~mm}$ distant from the surface to the prosthesis (C) (Figure 1). Five measurement sites were determined at each area (A, B, and C) so that each site was more than $100 \mu \mathrm{m}$ from an adjacent site, and was avoided entrapped air bubbles and blood. The average value was obtained.

In the control group, the point $\mathrm{A}$ was identified with the point $\mathrm{C}$. All other measurements were same as described.

\subsection{Young's Modulus}

The measurements for Young's modulus $(E)$ were conducted with the same location as the hardness on the "salami” specimen with a $0.7 \mathrm{~mm}$-thickness. Specimens were put in the bottom of a chamber in a scanning acoustic microscope (UH3, Olympus, Tokyo, Japan). The chamber was filled with distilled water at a controlled room temperature of $23^{\circ} \mathrm{C} \pm 1^{\circ} \mathrm{C}$. A $50-\mathrm{MHz}$ lens was used to generate and receive acoustic waves in pulse echo mode. The acoustic energy was reflected from the top surface of the specimen and the bottom surface of the specimen. The two reflections were seen on an oscilloscope and the time delay between them was measured on oscilloscope. Ultrasonic velocity $\left(V_{U}\right)$ was calculated as follows:

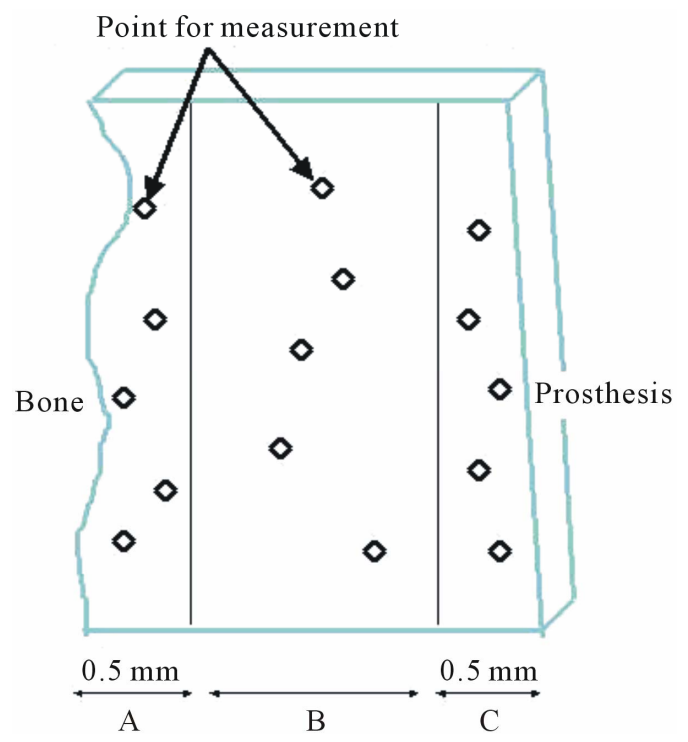

Figure 1. Bone cement specimen (Sliced). The measurements were performed at the area less than $0.5 \mathrm{~mm}$ distant from the surface to the bone (A), the middle area of the specimen (B), and the area less than $0.5 \mathrm{~mm}$ distant from the surface to the prosthesis (C). Five measurement sites were plotted at each area for Young's modulus as well as Knoop hardness.

$$
V_{U}=2 a / t
$$

where, $a$ : thickness of the specimen, $t$ : time delay

Young's modulus was calculated for each specimen according to the methods described by Briggs [12] and Turner et al. [13,14]

$$
\mu=\rho\left(V_{U} V_{S} / V_{L}\right)^{2}
$$

where, $\mu$ : shear modulus, $\rho$ : density of the specimen, $V_{S}$ : shear velocity, $V_{L}$ : longitudinal velocity

$$
E=2 \mu(1+\sigma)
$$

where, $\sigma$. Poisson ratio

$$
\text { In case of PMMA, } \begin{aligned}
\sigma & =0.34, V_{S} / V_{L}=1330 / 2700 \\
E & =0.65 \rho V_{U}^{2}
\end{aligned}
$$

Five measurement sites on each area (A, B, and C) were determined and the average was calculated.

In the control group, measurement sites for Young's modulus were also determined in the same manner as for the hardness measurement.

All procedures were performed at the room temperature of $23^{\circ} \mathrm{C} \pm 1{ }^{\circ} \mathrm{C}$. The results were analyzed by unpaired $t$-tests, considering $\mathrm{p}$ values of less than 0.05 to be significant.

\section{Results}

\subsection{Elements Presenting in the Retrieved PMMA Cement}

The following elements were detected: sodium, silicon, sulfur, chlorine, calcium, barium, and phosphorus (Table 2). Of these elements, barium and sulfur (barium sulfate) are found as a radiopaque material in the Simplex- $\mathrm{P}^{\circledR}$ cement ingredient lists.

\subsection{Knoop Hardness}

Knoop hardness of the retrieved PMMA cement was 17.6 \pm 2.1 (range, $13.4-20.6$ ), $17.0 \pm 1.7$ (range, 14.5 - 19.8), and $16.4 \pm 1.4$ (range, $14.6-18.4$ ) at the area of A, B, and $\mathrm{C}$, respectively. In the control group, the hardness was $18.5 \pm 3.7$ (range, $15.8-24.6$ ) and $17.0 \pm 1.4$ (range, $14.0-18.5)$ at the area of $A(C)$ and $B$, respectively. There was no significant difference between the retrieved cement and the control in each area (Table 3).

\subsection{Young's Modulus}

Young's modulus of the retrieved PMMA cement was $5.66 \pm 0.27 \mathrm{GPa}$ (range, $5.09-6.10$ ), $5.56 \pm 0.22 \mathrm{GPa}$ (range, 5.18 - 5.94), and $5.60 \pm 0.23 \mathrm{GPa}$ (range, 5.20 5.96) at the area of A, B, and C, respectively. In the control group, the modulus was $5.88 \pm 0.37 \mathrm{GPa}$ (range, 5.63 - 7.01) and $5.88 \pm 0.35 \mathrm{GPa}$ (range, $5.66-6.90$ ) at the 
Biodegradation of Polymethylmethacrylate Bone Cement May Not Be a Serious Issue in Total Hip Arthroplasty-Retrieval Study for Knoop Hardness and Young's Modulus

Table 2. Elements presenting in the retrieved polymethylmethacrylate bone cement samples.

\begin{tabular}{|c|c|c|c|c|c|c|c|}
\hline Sample No. & Sodium & Chlorine & Calcium & Phosphorus & Silicon & Barium & Sulfur \\
\hline $1-\mathrm{a}$ & & + & + & & + & + & + \\
\hline $1-b$ & & + & & & + & + & + \\
\hline 2 & & & & & & + & + \\
\hline $3-a$ & + & + & + & & & + & + \\
\hline $3-b$ & & & + & & + & + & + \\
\hline 4 & & + & & & + & + & + \\
\hline 6-a & & + & & & & + & + \\
\hline $6-b$ & + & + & + & & + & + & + \\
\hline $7-a$ & + & + & + & & + & + & + \\
\hline $7-b$ & & & + & & + & + & + \\
\hline $8-a$ & + & + & & + & + & + & + \\
\hline $8-b$ & & & + & & + & + & + \\
\hline 9 & + & + & + & & + & + & + \\
\hline
\end{tabular}

“+” indicates element present in sample.

Table 3. Hardness and young's modulus of the retrieved polymethylmethacrylate bone cement samples.

\begin{tabular}{|c|c|c|c|c|c|c|c|c|c|c|c|}
\hline \multirow[b]{2}{*}{$\begin{array}{c}\text { Sample } \\
\text { No. }\end{array}$} & \multirow[b]{2}{*}{$\begin{array}{l}\text { Width } \\
(\mathrm{mm})\end{array}$} & \multirow[b]{2}{*}{$\begin{array}{c}\text { Porosity } \\
(\%)\end{array}$} & \multirow[b]{2}{*}{ Density } & \multicolumn{4}{|c|}{ Knoop Hardness } & \multicolumn{4}{|c|}{ Young's Modulus } \\
\hline & & & & $\begin{array}{l}\text { (A) }<0.5 \mathrm{~mm} \\
\text { from the } \\
\text { bone }\end{array}$ & $\begin{array}{l}\text { (B) Middle } \\
\text { of the } \\
\text { sample }\end{array}$ & $\begin{array}{l}\text { (C) }<0.5 \mathrm{~mm} \\
\text { from the } \\
\text { prosthesis }\end{array}$ & Average & $\begin{array}{l}\text { (A) }<0.5 \\
\mathrm{~mm} \text { from } \\
\text { the bone }\end{array}$ & $\begin{array}{l}\text { (B) Middle } \\
\text { of the } \\
\text { sample }\end{array}$ & $\begin{array}{l}\text { (C) }<0.5 \mathrm{~mm} \\
\text { from the } \\
\text { prosthesis }\end{array}$ & Average \\
\hline $1-\mathrm{a}$ & 4.3 & 1.4 & 1.13 & 18.1 & 16.2 & 14.7 & 16.3 & 5.62 & 5.37 & 5.56 & 5.52 \\
\hline $1-b$ & 5.3 & 0.9 & 1.18 & 17.6 & 16.3 & 14.9 & 16.3 & 5.34 & 5.33 & 5.33 & 5.33 \\
\hline 2 & 4.3 & 2.3 & 1.27 & 17.4 & 14.5 & 16 & 16.0 & 5.87 & 5.69 & 5.74 & 5.77 \\
\hline $3-\mathrm{a}$ & 3.3 & 2.1 & 1.25 & 17.9 & 19.8 & 18.2 & 18.6 & 5.75 & 5.77 & 5.80 & 5.77 \\
\hline $3-b$ & 3.5 & 1.9 & 1.23 & 16.9 & 16.5 & 15.1 & 16.2 & 5.70 & 5.70 & 5.86 & 5.75 \\
\hline 4 & 5.3 & 1.6 & 1.21 & 19.2 & 19.6 & 16.7 & 18.5 & 5.38 & 5.27 & 5.20 & 5.28 \\
\hline $6-\mathrm{a}$ & 5.5 & 0.8 & 1.15 & 15.3 & 16.8 & 16.6 & 16.2 & 5.09 & 5.18 & 5.69 & 5.32 \\
\hline $6-b$ & 4.3 & 1.4 & 1.19 & 20.6 & 15.5 & 17.4 & 17.8 & 5.94 & 5.55 & 5.59 & 5.69 \\
\hline $7-\mathrm{a}$ & 4 & 3.1 & 1.20 & 20.6 & 16.5 & 18.4 & 18.5 & 5.61 & 5.69 & 5.38 & 5.56 \\
\hline $7-b$ & 4.3 & 1.6 & 1.19 & 18.2 & 18.7 & 18.4 & 18.4 & 5.67 & 5.61 & 5.50 & 5.59 \\
\hline $8-\mathrm{a}$ & 3.5 & 1.7 & 1.19 & 15.1 & 15 & 16.1 & 15.4 & 5.61 & 5.66 & 5.96 & 5.74 \\
\hline $8-b$ & 6.4 & 2.1 & 1.16 & 13.4 & 18.3 & 14.6 & 15.4 & 6.10 & 5.49 & 5.39 & 5.66 \\
\hline 9 & 2.8 & 2.8 & 1.23 & 18.1 & 17.2 & 16.3 & 17.2 & 5.84 & 5.94 & 5.84 & 5.87 \\
\hline Average & 4.4 & 1.8 & 1.20 & 17.6 & 17.0 & 16.4 & 17.0 & 5.66 & 5.56 & 5.60 & 5.61 \\
\hline S.D. & 1.0 & 0.7 & 0.04 & 2.1 & 1.7 & 1.4 & 1.2 & 0.27 & 0.22 & 0.23 & 0.19 \\
\hline \multicolumn{12}{|c|}{ Control $(\mathrm{n}=20)$} \\
\hline Average & 5 & 0.1 & 1.25 & 18.5 & 17 & $18.5^{*}$ & 17.8 & 6.19 & 5.88 & $6.19^{* *}$ & 6.04 \\
\hline S.D. & 0 & 0 & 0.03 & 3.7 & 1.4 & $3.7^{*}$ & 1.5 & 0.21 & 0.12 & $0.21^{* *}$ & 0.13 \\
\hline$t$-test & & & & N.S. & N.S. & N.S. & N.S. & $\mathrm{p}=0.001$ & $\mathrm{p}<0.001$ & $\mathrm{p}<0.001$ & $\mathrm{p}<0.001$ \\
\hline
\end{tabular}

": same as the data (A) (Hardness); ${ }^{* *}$ : same as the data (A) (Young's modulus).

area of $\mathrm{A}(\mathrm{C})$ and $\mathrm{B}$, respectively. The moduli were significantly less for the areas $\mathrm{B}$ and $\mathrm{C}$ than those of the control $(p<0.05)$ However, the differences of the moduli between the retrieved PMMA cement and the control were approximately $7 \%$ of the values in average (Table 3). 


\section{Discussion}

All of the retrieved PMMA bone cement samples had yellow-brown discolored band which was observed in the area contacted with bone tissue (Figure 2). There was a scent of urea or ammonium at the time of cutting the samples. These physical findings suggested the presence of bilirubin $\left(\mathrm{C}_{33} \mathrm{H}_{36} \mathrm{~N}_{4} \mathrm{O}_{6}\right)$ by color or urea $\left(\mathrm{CO}\left(\mathrm{NH}_{2}\right)_{2}\right)$ and by smell or both in the cement. Unfortunately, our machine was unequipped to detect these chemical compounds. However, sodium, chlorine, calcium, and phosphorus were detected in the retrieved PMMA bone cement. These chemical elements were usually present in human plasma and they seemed to infiltrate into the cement. All of these elements were not always detected in the samples. This might be due to threshold of the machine. There did not seem to be a good explanation for the presence of silicon. It is unknown whether the presence of the elements deteriorates the cement. In dentistry, composite resins, such as Bis-GMA with silica filler, have been often used for reconstruction of teeth. The resins included the filler so that the mechanical properties and resistance to wear could be increased. Degradation, however, occurred by infiltration of water and variable chemical substances into the resins [15]. This might cause degradation of the cement.

Concerning biodegradation of the cement, Hughes et al. [16] reported that scission-based structural degradation occurred in the acrylic bone cement with FTIR analysis. Ries et al. [17] mentioned that fracture toughness of Simplex cement did not correlate with time in vivo between 1 month and 27 years of the samples retrieved from 43 patients undergoing revision total hip arthroplasty.

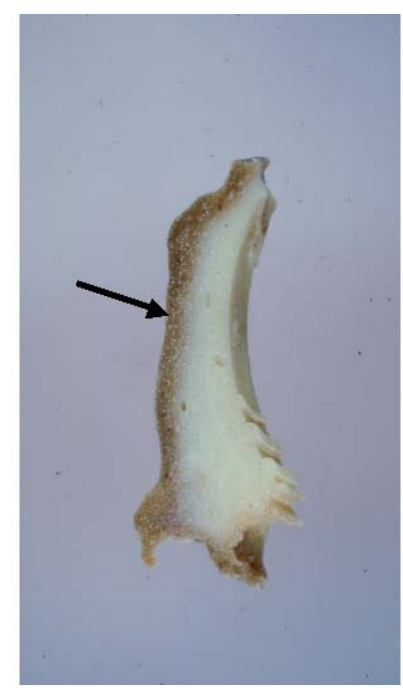

Figure 2. Retrieved bone cement sample used in the acetabulum (No. 1-a). The sample had yellow-brown discolored band (allow) which was observed in the area contacted with bone tissue.
Oonishi et al. [18] reported that the bending strength in CMW1 cement after implantation decreased with increasing time in vivo and depended on the density of the bone cement, which we assume to be determined by the porosity.

To investigate and evaluate all the mechanical properties of the retrieved cement, such as tensile, compressive, impact, flexural, and shear strengths, hardness, and Young's modulus were not difficult; however, some difficulties did occur in evaluating the mechanical strengths of the samples. There were extra inclusions, such as air or blood entrapments or both, and laminations in the samples. These inclusions affected the mechanical strengths. Most of the retrieved cement was made by manually mixing in air (no vacuum mixing) when the patients had total hip arthroplasty. Porosity of the cement caused by entrapment of air bubbles was inevitable in clinical practice. De Wijn et al. [19] reported that the overall effect of porosity caused by entrapment of air bubbles was approximately $50 \%$ reduction in the impact and flexural strength, by using specimens with a $20-\mathrm{mm}$ square cross section. Gruen et al. [20] confirmed that the presence of blood at the interface further weakened the bond to approximately $25 \%$ (tension) and $36 \%$ (shear) of the virgin strengths of the cement, by using specimens $13 \mathrm{~mm}$ in diameter and $114 \mathrm{~mm}$ long. Holm [21] also tested CMW, Simplex and Palacos R bone cement by using specimens a size of $4 \times$ $10 \times 110 \mathrm{~mm}$ and observed that a $3 \mathrm{ml}$ blood inclusion decreased the flexural strength significantly in all of the brands. The ratios of the entrapped air bubbles or blood were not constant among the retrieved samples, however, it was impossible to measure the amount and distribution of these inclusions in the cement. In addition, it was necessary to make several specimens, such as cylinders 12 $\mathrm{mm}$ high and $6 \mathrm{~mm}$ in diameter for evaluating compressive strength or beams with $1.5 \times 10 \times 25 \mathrm{~mm}$ size for evaluating flexural strength, as suggested by ASTM standards $[22,23]$. Thus, these strengths seemed to be unreliable in the retrieved study for evaluating the effect of time. Unfortunately, since specimens for these strength tests were too large to exclude the inclusions, such as air bubbles or blood, it was impossible to neglect its effects. These sizes were too large to gain enough number of the specimens with adequate shape and size, because the retrieved samples were limited in their shape and size.

Porosity of the cement caused by entrapment of air bubbles was observed in all of the retrieved specimens which were made by mixing in air at the time of the previous surgeries. Laminations and blood entrapment were also recognized in our specimens. To eliminate the influence of the inclusions, we focused on the measurement of Knoop hardness and the evaluation of Young's modulus by scanning acoustic microscopy. Because these pa- 
rameters were proven to be evaluated by $0.1 \mathrm{~mm}$ distance at random on the surface of sectioned specimens, it was possible to exclude the areas with entrapped air bubbles or blood, and laminations from the measurement $[13,24]$. As a result, the size of the specimens was 10 cubic $\mathrm{mm}$ enough to determine these parameters.

Knoop hardness measurements were used as the indicators of the relative degree of cure in light-activated composite resins [24]. Polymerization of the resins depended upon the formation of free radicals. The presence of oxygen could have caused retardation of polymerization if oxygen reacted with the free radicals. As a result, the hardness gradually decreased with increasing depth in the light-activated composite resins. In our study, the hardness was unrelated with depth. The reason for this was probably to be explained that our PMMA samples were polymerized by hand mixing.

To our knowledge, little has been reported on in vivo changes of the hardness of the PMMA cement for long term. In Bis-GMA-based dental composite resins, softening of the matrix was recognized when the resins were exposed $75 \%$ ethanol solution [15]. Our study demonstrated that the hardness of the retrieved PMMA cement was not changed more than twelve years in vivo. The hardness was decreased at twenty five years postoperatively (sample No.8), however, its ratio to normal hardness of PMMA cement was more than $80 \%$.

Young's moduli of solid matter were generally determined by one of the following three methods: 1. to measure the strain by applying a known compressive, tensile, flexural or torsional force to a block of the material; 2. to measure the natural frequency of vibration of a rod of the material simply supported at its ends and heavily loaded by a mass in the middle; and 3. to measure the velocity of sound in the material, as the velocity depending on Young's modulus and the density [12]. The conventional methods (No. 1 and 2) usually needed relatively large specimens, which might reflect the influence of the inclusions, such as air or blood entrapment. The best of all methods of measuring Young's modulus of small specimens are acoustic methods (No. 3) [25]. Acoustic testing using a scanning acoustic microscope allowed measurement of ultrasonic velocities in PMMA cement with a resolution of about $60 \mu \mathrm{m}$. This was also useful to exclude the influences of the entrapped air bubbles or blood from the measurement of Young's modulus. In addition, the results were confirmed to reduce experimental error, achieving much greater precision than the conventional methods [14].

In the literature, Young's moduli of Simplex cement determined by using the conventional method No. 1 were varied of 0.85 (by torsion) [26,27], 2.14 (by compression) [26,27], 2.35 - 2.84 (by flexure) [19], 4 and 2.55 GPa (by tension) [28]. Holm [21] measured Young's modulus by using the conventional method No. 2 and indicated that a $3 \mathrm{ml}$ blood additive decreased the modulus significantly in all brands of CMW, Simplex and Palacos R bone cement, as well as the flexural strength. However, the moduli determined by the conventional methods $(0.85-2.84$ $\mathrm{GPa})$ were relatively lower than our results (5.09- 6.45 $\mathrm{GPa}$ ). The reason for this discrepancy was probably to be explained that the former methods give bulk properties of PMMA cement including the effects of pores and the latter was calculated by measuring ultrasonic velocities in small areas of the cement reflecting solid PMMA without pores.

Although Young's moduli of the retrieved polymethylmethacrylate cement were significantly decreased during twelve or more years postoperatively in our study, the differences of the moduli between the retrieved cement and the control were only $7 \%$ of the values in average (Table 3). In dentistry, Oshida et al. reported that modulus of elasticity of dental composite resins reduced by increasing the amount of absorbed water up to three weeks [29]. In the present study, all of the samples including the control were also immersed in physiological saline solution for six weeks or more. If the amount of absorbed water in the PMMA cement increases over a long time, this is an explanation for reduction of the modulus. In the regression model of the retrieved bone cement, it was supposed that combination among molecules was cut off in several areas compared with the cement just after polymerization (Figure 3 ).

The components of Simplex- $\mathrm{P}^{\circledR}$ cement were not changed between 1970s and 1990s. The retrieved cement specimens were manually mixtured in air until the first half of 1980s. Therefore, the control samples also were made by manually mixing in air. Biomechanical properties of the cured PMMA bone cement, such as Young's modulus, might be affected by room temperature and humidity at the time of preparing, as well as porosity, inclusions, or laminations of the cement. In fact, there was difference in the modulus between the sample No. 6-a and -b, as well as No. 1-a and -b (Table 3). The condition at the

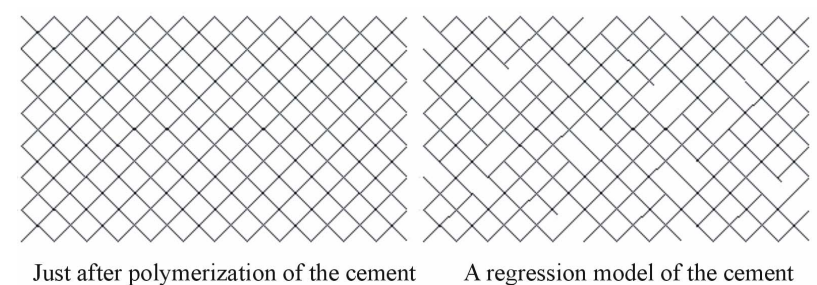

Figure 3. Microstructure of the polymethylmethacrylate bone cement. In the regression model, combination among molecules was cut off in several areas, so called scission-based structural degradation. 
manually mixing might influence on the modulus as compared with the time duration in vivo.

It is difficult to evaluate objectively in vivo deterioration or aging of the PMMA cement for a long time. As regards the hardness and Young's modulus, however, the measurements were easily performed even if the samples were restricted in size and shape. The decreased Young's modulus of the cement was only $7 \%$ in average and still ranked between the moduli of the cancellous bone and the cortical bone. We concluded that biodegradation evaluated by Knoop hardness and Young's was not a serious issue for mechanical loosening of the hip prostheses, because the retrieved PMMA bone cement had no change in hardness and a slight decrease in Young's modulus between twelve and twenty-five years in vivo.

\section{Acknowledgements}

The authors wish to thank Charles H. Turner, Ph.D., Director of Orthopaedic Research, Department of Orthopaedic Surgery, Indiana University School of Medicine, Yuichi Takano, M.D., Ph.D., Department of Orthopaedic Surgery, Akita Red Cross Hospital, Masashi Miyazaki, D.D.S., Ph.D., Department of Operative Dentistry, Nihon University School of Dentistry, and Yoshiki Oshida, B.S., M.S., Ph.D., Department of Restorative Dentistry, Dental Materials Research Laboratory, Indiana University School of Dentistry, for their advice and excellent technical assistance. We acknowledge Keith B. Moore, Ph.D., Professor, Department of Dental Materials, Indiana University School of Dentistry, Thomas W. Bauer, M.D., Ph.D., Departments of Pathology and Orthopaedic Surgery, The Cleveland Clinic Foundation for their advice. We also wish to thank Mr. Bob Hastings P.E., Group Manager, Biomechanical Technologies, DePuy Inc., for his excellent technical assistance.

\section{REFERENCES}

[1] J. Charnley, "Anchorage of the Femoral Head Prosthesis to the Shaft of the Femur," The Journal of Bone \& Joint Surgery, Vol. 42-B, 1960, pp. 28-30.

[2] S. Saha and S. Pal, "Mechanical Properties of Bone Cement: A Review," Journal of Biomedical Materials Research, Vol. 18, No. 4, 1984, pp. 435-462. http://dx.doi.org/10.1002/jbm.820180411

[3] L. Neumann, K. G. Freund and K. H. Sørenson, "LongTerm Results of Charnley Total Hip Replacement. Review of 92 Patients at 15 to 20 Years," The Journal of Bone \& Joint Surgery, Vol. 76-B, 1994, pp. 245-251.

[4] K. R. Schulte, J. J. Callaghan, S. S. Kelley and R. C. Johnston, "The Outcome of Charnley Total Hip Arthroplasty with Cement after a Minimum Twenty-Year Follow-Up. The Results of One Surgeon," The Journal of Bone \& Joint Surgery, Vol. 75-A, 1993, pp. 961-975.
[5] B. M. Wroblewski and P. D. Siney, "Charnley Low-Friction Arthroplasty of the Hip: Long-Term Results," Clinical Orthopology, Vol. 292, 1993, pp. 191-201.

[6] W. L. Jaffe, R. M. Rose and E. L. Radin, "On the Stability of the Mechanical Properties of Self-Curing Acrylic Bone Cement," The Journal of Bone \& Joint Surgery, Vol. 56-A, 1974, pp. 1711-1714.

[7] J. T. Scales and J. M. Zarek, "Biomechanical Problems of the Original Judet Prosthesis," British Medical Journal, Vol. 1, 1954, p. 1007. http://dx.doi.org/10.1136/bmj.1.4869.1007

[8] A. J. C. Lee, R. S. M. Ling and S. S. Vangala, "The Mechanical Properties of Bone Cements," Journal of Medical Engineering \& Technology, Vol. 2, 1977, pp. 137-140. http://dx.doi.org/10.3109/03091907709160626

[9] W. Rostoker, P. Lereim and J. O. Galante, "Effect of an in Vivo Environment on the Strength of Bone Cement," Journal of Biomedical Materials Research, Vol. 13, 1979, pp. 365-370. http://dx.doi.org/10.1002/jbm.820130303

[10] U. Holz, W. Hemminger and H. Gasse, "Mechanishe Untersuchungen an Explantierten und Frischen Knochenzementen," Archives of Orthopaedic and Trauma Surgery, Vol. 91, 1979, pp. 365-370.

[11] V. Fano, I. Ortalli and K. Pozela, "Porosity in Composite Resins,” Biomaterials, Vol. 16, 1995, pp. 1291-1295. http://dx.doi.org/10.1016/0142-9612(95)91043-X

[12] A. Briggs, "Acoustic Microscopy," Clarendon Press, Oxford, 1992

[13] K. Hasegawa, C. H. Turner, R. R. Recker, E. Wu and D. B. Burr, "Elastic Properties of Osteoporotic Bone Measured by Scanning Acoustic Microscopy," Bone, Vol. 16, 1995, pp. 85-90.

[14] C. H. Turner and D. B. Burr, "Basic Biomechanical Measurements of Bone: A Tutorial," Bone, Vol. 14, 1993, pp. 595-608 http://dx.doi.org/10.1016/8756-3282(93)90081-K

[15] M. Kawaguchi, T. Fukushima and K. Miyazaki, "Variables Affecting the Degradation of Dental Composite Resins. 2. SEM Investigation of Aged Composite Resin," Dental Materials, Vol. 13, 1994, pp. 116-121.

[16] K. F. Hughes, M. D. Ries and L. A. Pruitt, "Structural Degradation of Acrylic Bone Cements Due to in Vivo and Simulated Aging," Journal of Biomedical Materials Research A, Vol. 65, 2003, pp. 126-135. http://dx.doi.org/10.1002/jbm.a.10373

[17] M. D. Ries, E. Young, L. Al-Marashi, P. Goldstein, A. Hetherington, T. Petrie and L. Pruitt, "In Vivo Behavior of Acrylic Bone Cement in Total Hip Arthroplasty," Biomaterials, Vol. 27, 2006, pp. 256-261. http://dx.doi.org/10.1016/i.biomaterials.2005.05.103

[18] H. Oonishi, H. Akiyama, M. Takemoto, T. Kawai, K. Yamamoto, T. Yamamuro, H. Oonishi and T. Nakamura, "The Long-Term in Vivo Behavior of Polymethyl Methacrylate Bone Cement in Total Hip Arthroplasty," Acta Orthopaedica, Vol. 82, 2011, pp. 553-558. http://dx.doi.org/10.3109/17453674.2011.625538

[19] J. R. de Wijn, T. J. J. H. Sloff and F. C. M. Driessens, “Cha- 
racterization of Bone Cement," Acta Orthopaedica Scandinavica, Vol. 46, 1975, pp. 38-51. http://dx.doi.org/10.3109/17453677508989190

[20] T. A. Gruen, K. L. Markolf and H. C. Amstutz, "Effects of Laminations and Blood Entrapment on the Strength of Acrylic Bone Cement," Clinical Orthopaedics, Vol. 119, 1976, pp. 250-255.

[21] N. J. Holm, "The Modulus of Elasticity and Flexural Strength of Some Acrylic Bone Cements," Acta Orthopaedica Scandinavica, Vol. 48, 1977, pp. 436-442. http://dx.doi.org/10.3109/17453677708989727

[22] "Standard Specification for Acrylic Bone Cement," Annual Book of ASTM Standards, F451-95, Philadelphia.

[23] "Standard Test Methods for Flexural Properties of Unreinforced and Reinforced Plastics and Electrical Insulating Materials [Metric]," Annual Book of ASTM Standards, D790M-86, Philadelphia.

[24] H. Onose, H. Sano, H. Kanto, S. Ando and T. Hasuike, "Selected Curing Characteristics of Light-Activated Composite Resins," Dental Materials, Vol. 1, 1985, pp. 48-54. http://dx.doi.org/10.1016/S0109-5641(85)80024-5
[25] M. F. Ashby and D. R. H. Jones, "Engineering Materials 1: An Introduction to Their Properties and Applications," Pergamon Press, Oxford, New York, Seoul, Tokyo, 1993.

[26] A. J. C. Lee, R. S. M. Ling and J. D. Wrighton, "Some Properties of Polymethylmethacrylate with Reference to Its Use in Orthopaedic Surgery," Clinical Orthopaedics, Vol. 95, 1973, pp. 281-287.

[27] A. J. C. Lee and R. S. M. Ling, "Further Studies of Monomer Loss by Evaporation during the Preparation of Acrylic Cement for Use in Orthopaedic Surgery," Clinical Orthopaedics, Vol. 106, 1975, pp. 122-125. http://dx.doi.org/10.1097/00003086-197501000-00017

[28] R. P. Kusy, "Characterization of Self-Curing Acrylic Bone Cements," Journal of Biomedical Materials Research, Vol. 12, 1978, pp. 271-305. http://dx.doi.org/10.1002/jbm.820120304

[29] Y. Oshida, A. Hashem and R. Elsalawy, "Some Mechanistic Observation on Water-Deteriorated Dental Composite Resins," Biomedical Materials and Engineering, Vol. 5, 1995, pp. 93-115. 